Pakistan Journal of Education Vol.36, No.3, 2019, 145-162

\title{
Implications of Cultural Capital in Women's Higher Education Participation and Social Mobility
}

\author{
Muhammad Uzair-ul-Hassan \\ Iram Parveen ** \\ Sobia Saleem *
}

\begin{abstract}
Equality of opportunity in higher education participation is a basic right of people in a society that leads to their social mobility in the long run. Benadusi (2002) endorsed Bourdieu's explanations that cultural capital acts as an empowering force that predetermines equality/inequality of educational opportunity of people in a society. The study, thus, aimed to explore cultural capital as means of participation in higher education and eventually social mobility of women. A cross sectional survey was used to collect data from 103 working and 97 non-working women using purposive and convenience sampling. The study found positive relation of cultural capital of women with their participation in higher education and social mobility. Significant difference was also found between cultural capitals of working and non- working women, where cultural capital of working women was higher as compared to non-working. The study, therefore, put to light strong connection of cultural capital and education for women in a society. i.e. higher the cultural capital, higher the participation rate in higher education, where education itself keeps enhancing cultural capital of women. It is concluded that higher education for women must be the core value of our society. Women solemnity and their struggle for participation in higher education becomes a source of transforming their lower cultural capital into higher cultural capital. This shift from lower to higher cultural capital ultimately leads women to social mobility in a society.
\end{abstract}

Keywords: cultural capital, women, social mobility, participation, higher education

\footnotetext{
*Associate Professor.uhassan74@gmail.com

** Lecturer, University of Sargodha, Sargodha

** Graduate, University of Sargodha, Sargodha
} 


\section{Introduction}

In Pakistan, social qualities and standards emphatically affect women's position in the public eye. Despite the fact that the patriarchal structure is not standardized over the entire nation, by and large, society is male-dominant. According to Shah, Khan, Naushad, Jadoon and Alam (2006), most people kept the view that if women are enlightened, menwould lose their respect. Even now-a-days, most of the parents of women don't allow them to do paid job with males, avail oversees scholarship for higher education and do jobs in other countries rather confine them for household tasks. Since, women lives mostly center round their conventional roles, like taking care of most household tasks, doing farm work, cleaning the house, washing clothes and cooking food, their position mostly remained dependent on their husbands and parents.Equality of opportunity in higher education participation is a basic right of both women and men in a society that leads to their social mobility in the long run. Benadusi (2002) endorsed Bourdieu's (1977) explanations that cultural capital acts as an empowering force that predetermines equality/inequality of educational opportunity of people in a society. Family background of women also affects their participation in higher education and success. There is a strong relation between socioeconomic conditions of woman and their success. Social background restricts participation in higher education, changes outcomes and social mobility.

\section{Understanding Cultural Capital}

Cultural capital denotes to the status of an individual in a society. The status comprises of social, economic, family or any other components that differentiates one individual to another. According to Gorbunova, (2009), cultural capital is a person's wealth in the form of basic values, standards, education, rational, ethical and social appearances that regulates qualified ability and is applied in social events, taking extra socioeconomic assistances and legitimize position, role, and authority. Cultural capital is for the most part transmitted through the family. The term cultural capital is the combination of nonmonetary powers like family foundation, social class, changing interests in and commitments to instruction, distinctive assets, and so on that impacts our scholarly achievement.

Cultural capitalalso consists of a set of attitudes, practices and beliefs of an individual in a culture. These components of a culture are 
fundamental to the functioning of different societies. Culture is expressed in a particular society's values and customs, which evolves over time as they are transmitted from one generation to another (Throsby, 1999). Cultural capital of an individual can also be seen through the lens of a society. Society can shape our perspective of the world (Rabbani, Zeeshan, and Saleem, 2015). The cultural capital alludes to the social advantages like cultural knowledge, attitude and disposition, language, linguistics and interpersonal skills, manners, tastes (music, arts, food, dress etc), arbitrary, education, intellect and physical appearance. Sans doubt, this is advantage for transcendent but families have to maintain this advantage to the next generation through its transformation. This is exactly what Laureau (2000) concluded that better classes have to transform the cultural resources into "activated cultural capital".

\section{Culture Capital and Educational Institutions}

Cultural capital is very significant in the study of educational development and social class reproduction (Yamamoto and Brinton, 2015). Brooks (2008) discussed that schools play vital role in reproducing social classes and unbalancing the society. He referred to Bourdieu's (1977) explanations, that educational institutions themselves support social inequalities due to variations in students' linguistic and cultural competence and differing levels of familiarity with the dominant cultural capital. Bourdieu (1977) found that societal class has important role in the financial, societal and cultural possession and that the values of the educational organization are usually aligned with the home situation of dominant classes, where dominant classes seek the edge. This multiplies the disparities within educational institutes by rewarding and providing good environment of culture to the students with high cultural capital (Wood, 2008).

Students from lower social classes having weak cultural capital leads to their low educational achievement. Bourdieu also explained that cultural capital is significantly linked to educational outcomes. According to Sullivan (2002), lower social class students have rare chance to succeed in the educational framework as educational achievements differ based on class differences, rather lead to class reproduction in the society, where schools rewards are based only on cultural capital of students and teachers also, more effectively communicate with those students who belong to elite status. DiMaggio (1982) also endorsed that students from better classes receive more 
attention from teachers than those having weak cultural capital. Also, on the other hand, students having better cultural capital take an edge in terms of better facilitation at home with books and various resources that enhance educational achievement.

Higher education participation of youth in the society is also linked to cultural capital. According to Blanden and Machin (2004), to a certain extent, education is extremely benefited for those persons who belongs to rich families. In spite of the reality, numerous children from higher income backgrounds take part in higher education. To minimize this disparity between classes, governments often offer scholarships to the needful, thus, discrimination exist in higher education between different social classes and also in ethnicity, gender and mainly in access to elite class educational institution (Brooks, 2008). For instance, while both male and female students pick business over some other professions, males get comparably high grades in designing, pure sciences and software engineering than females(Dumais, 2002).

Upper classes not only enjoy dominance in the society, but also penetrate in the society by silently shaping up the society. Therefore, the upper classes maintain their social status and rule the society by getting all the opportunities required to maintain position in a society while prohibit others from benefited social arrangements or high status groups. They invest the capital in children, which in future, returns in the form of income by providing respect and care, and make their own precise distinguishing cultural styles, tastes and behaviors through which they dominate the society(DiMaggio, 1982; Jaeger, 2010).

Cultural capital has strong implications in early familial background for pupils' advancements(Yamamoto and Brinton, 2015). According to Brooks (2008), parental education is linked to children's development in higher education.Parental cultural capital keep influencing children's educational achievement, such that children with educated parents and high financial status backgrounds perform superior to lower financial status backgrounds, nonetheless, empirical evidences also show that the cultural capital of parents and their youngsters were observed to be autonomous of each other. (Tzanakis, 2011) Similarly, students having better cultural capital have better language proficiency, which has a significant place in academic achievement and is one of greatest significant factors in the educational success or disappointment of academic performance. (Valdez et al., 2012).The results of Košutić (2017) indicated that cultural capital had statistically significant 
correlation with school performance. According to Xiulan and Yan (2019),cultural capital is not always obtained through intergenerational transmission: lower-class fulfills family's disadvantages if actively acquires advantaged cultural capitalforupward social mobility.

\section{Cultural Capital, Women's Participation in Higher Education and Social Mobility}

Lower cultural capital of women limits their participation in higher education that lads to their social mobility in the long run.Social mobility refers to the women's evolution or chances of movement between upper social groups. It includes the lifestyle, education, interest, taste, income; security of employment, opportunities for career advancement etc.The women's social mobility has also been dependent on a wide range of variables such as geological area (urban/country), instructive status, societal position and class, and age. Strategies on women's mobility exist at the national and state levels in numerous areas, including wellbeing, training, monetary, sex based brutality, and political support. Getting women higher education opens windows for women to bring numerous advantages and opportunities for social mobilization.

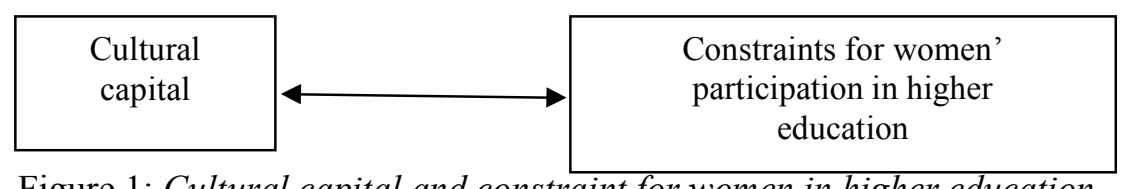

Figure 1: Cultural capital and constraint for women in higher education participation

According to Aldridge (2001), social mobility is the development between various social gatherings, and the points of interest and detriments that run with this regarding salary, security of service. Social mobility is estimations in which a people have opportunity to believe that how individuals recoup their place "in the public arena". Social mobility has influence on the behaviour and disposition of individuals. According to Younas, Sakhawat, Chaudhry and Nasir (2015), social mobility is a perfect field of investigation that it could be intentional of its differing measurements. Galiani, (2007)elaborated that social mobility is a state in which the financial condition of an individual does not reliant on parental wage or family background. Equitable 
education is important for social mobility of women. Absence of social mobility suggests disparity of chance, monetary effectiveness. According to Nazimuddin (2014), in the vertical social mobility, the individuals have to achieve high education, and have to be rich to move upward in the social chain of importance. Women can have better social mobility through higher education participation that will also increase their cultural capital and this could be vice versa.

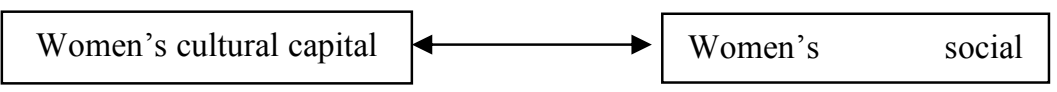

Figure 2: Cultural capital and constraints for women in social mobility

It is a fact that cultural capital is necessary for social mobility. Individuals socially mobilize with education and raise their cultural status for better survival. Xiulan and Yan (2019) concluded that cultural capital not only plays the vital function to push upward mobility of lower class but also upholds the advantages of the upper classes in a society. Social mobility is such sort of methodology in which people and families -move from one social position to the higher one to raise their economic wellbeing. According to Younas et al. (2015), the most significant determinants o fsocial mobility are occupation and wealth. In a progressive society, the proficiencies of upper and working classes are viewed as profitable capital. Yosso (2005) concluded that, if someone is not born in literate families, one could get to the proficiencies of the upper class society and would ultimately socially mobilized through formal schooling. n Pakistan, women's position in society is powerfully influenced by socio-cultural values and norms (Klein and Nestvogel 1992). People with higher education and better employment are regarded more in the general society (Nazimuddin, 2014). Women's social mobility brings certainty among women.

In Pakistan, higher educational institutions have traditional culture, which transforms women to become subordinate rather to empower. The educational institutions shape boys and girls in a different ways (Qureshi, Pirzadoand Nasim 2007). It is regrettable that there is a strong bias against women and in that way there is no equal opportunity for them to enhance their socio-economic status albeit some efforts are visible in some institutions. This ignoring attitude towards women represents in many fields. Education is the primary element in the socio-economic 
development of a country, however, women access in the field of education has not been fairly treated. According to Nath (2014), men prepare the women to become better wives and mothers in Pakistan. Education grooms women's personality and create confidence in them. Nath's findings (2014) concluded that women do not enjoy the advantage of the education and if half of a society's members are lagged behind, it will create hindrance to the development in Pakistan. The educational institutions established add to women's subordination as opposed to enabling them (Nath, 2014).

Constraints prevail for women that limit them to avail opportunities in higher education, scholarships and job placement and keep them confined to house boundaries and walls. Sans doubt, such constraints lower the cultural capital of women that has implications on women's participation in higher education as well as their social mobility in a society. The intended study sought to explore relationship between cultural capital, constraints for women in higher education participation and social mobility and those factors, which confine women to house boundaries and walls. The purpose is to investigate either cultural capital affects women participation in higher education and their social mobility or not? The study, thus, aimed to explore cultural capital as means of participation in higher education and eventually social mobility of women.

In the context constituted above, researchers formulated following objective that revolve around the study on cultural capital, women social mobility and their participation in higher education.

1. Examine the cultural capital of women with respect to higher education participation and social mobility.

Researchers were interested to find out the answers of the following research questions developed to fulfill the objective:

1. Is there any significant difference between the cultural capital of working and not working, and urban and rural women?

2. Is there any significant difference in mean scores of women's social mobility with respect to their age, qualifications and marital status?

3. Is cultural capital and constraints for women to participate in higher education and social mobility, correlated?

4. Are constraints for women participation in higher education and their social mobility correlated? 


\section{Methodology}

The research study was descriptive in nature and cross-sectional survey design was used to explore cultural capital and constrains for women in higher education participation and social mobility. The population for this study comprised of women either working in public, private, or semi-governmental sectors or non-working (households) women from city Sargodha. By using convenience purposive sampling, 300 women were selected for the purpose of data collection. One of the researchers personally visited the respondents and collected the data. Out of 300 questionnaires, total return rate for this study was 66\% (200 questionnaires), 103 (51\%) working women and 97 (49\%) non-working women.

\section{Research Instrument}

The self-developed questionnaire contained demographic information in the first part and the second was purport for gaining in depth information about cultural capital and constraints for women in higher education participation and social mobility. After completion the process of instrument validation, 50 items were finalized.

Table 1

Number of Items of cultural capital, participation in higher education and social mobility included in the questionnaire

\begin{tabular}{clc}
\hline Sr. No. & Factors & No. of items \\
\hline 1 & Literacy & 2 \\
2 & Social solidarity & 3 \\
3 & Family support & 2 \\
4 & Facilities & 3 \\
5 & Children care & 4 \\
6 & Economics & 3 \\
7 & Parents Consciousness & 2 \\
8 & Learner Interest & 2 \\
9 & Communication & 4 \\
10 & Teaching and learning & 3 \\
11 & Family cooperation in higher education & 3 \\
12 & Lifestyle/leisure time activities & 3 \\
13 & Recreation & 5 \\
14 & Access to information and mass media & 4 \\
15 & Parents Appreciation & 4 \\
16 & Husband's support & 3 \\
\hline
\end{tabular}

All items were measured on a 7-point rating scale with response format ranging from 0 (Not Applicable), 1 (Strongly Disagree), 2 
(Moderately Disagree), 3 (Slightly Disagree), 4 (Slightly Agree), 5 (Agree) and 6 (Strongly Agree).Age measured 6 categories of years ranking from 18 to 43 and above. Education level was measured in years of university education with five categories ranging from ' 1 ' to ' 6 .' Nature of job was measured as a dichotomous variable coded such as, ' 1 ', for regular and ' 2 'for contractual. Type of organization was measured by three categories, i.e. ' 1 ' for public,' 2 'for private and ' 3 'for semigovernment. Locality was measured as a dichotomous variable coded as ' 1 ' for urban, '2' for rural. Pay level was measured by six categories of monthly income ranging from 'below 5000 to 65000-and-above'. Language was measured by three categories, i.e. ' 1 ' for Punjabi, '2'for Urdu and ' 3 'for English. Marital status was measured by fivecategories, '1' for married, '2' for unmarried, '3' for divorced, '4' for separate and ' 5 ' for widow. Father and husband's occupation was measured by sixcategories, ' 1 ' for teacher, '2' for doctor, '3' for lawyer, '4' for self-employed, '5' for farmer and ' 6 'represented for others. Father and husband's pay level was measured by six categories of monthly income ranging from ' 5000 to 65,000 -and-above. Number of children was measured by four categories 0 to 8 . Family status was measured as a dichotomous variable coded such that ' 1 'for single, '2' for joint family. Duration of marriage was measured in years by fivecategories, ' 0 ' to more than ' 20 '. Researchers conducted 35 questionnaires for pilot testing before final data collection to ensure the reliability and quality of questionnaire. Reliability, in the form of internal consistency in responses (Cronbach Alpha) came as 0.75. Pilot testing indicated researchers to exclude three statements, statements \# 3, 10 and 22, due to less responses of respondents. After excluding these statements, reliability was increased from 0.75 to 0.77 . The researchers personally visited different houses and organizations in Sargodha. After the data collection, the researcher checked the entire questionnaire and discarded unclear, incomplete, improper filled questionnaires from the data before final data entry. For data analysis, inferential and descriptive statistics were used. Inferential statistics such as $t$-test, one way ANOVA and Correlation were conducted to investigate statistical relationship and differences between respondents' views. 


\section{Results}

Table 2

Comparison of cultural capital of "working" and "non-working women", urban and rural women

\begin{tabular}{ccccccc}
\hline Variable & Level & $\mathrm{N}$ & Mean & $\mathrm{SD}$ & $\mathrm{t}$ & $\mathrm{p}$ \\
\hline $\begin{array}{c}\text { Working } \\
\text { status }\end{array}$ & Working & 103 & 64.60 & 13.53 & & \\
\hline \multirow{2}{*}{ Locality } & Household & 97 & 58.02 & 12.18 & 3.607 & .000 \\
& Urban & 140 & 63.00 & 13.58 & 2.471 & .014 \\
\hline
\end{tabular}

The above table indicates that there is a significant difference between cultural capital of working and non-working women as shown by the value of $\mathrm{t}=3.607(\mathrm{p}=0.000<0.05)$. It shows difference that cultural capital of working women is high due to the value of Mean = 64.6 as compared to non-working women with Mean $=58.02$. The results also indicates that there is a statistically significant difference between cultural capital of urban and rural women, as shown by the value of $\mathrm{t}=$ $2.471(\mathrm{p}=0.014<0.05)$. It is inferred that the urban women had a higher cultural capital with the value of Mean $=63.00$, as compared to rural women with Mean $=57.89$.

Table 3

One-Way ANOVA Social mobility of different age groups, different qualification, and marital status

\begin{tabular}{|c|c|c|c|c|c|}
\hline Social mobility & SS & $\mathrm{df}$ & MS & $\mathrm{f}$ & $\mathrm{p}$ \\
\hline \multicolumn{6}{|l|}{ Different age groups } \\
\hline Between Groups & 4172.79 & 5 & 834.558 & \multirow{2}{*}{3.437} & \multirow{2}{*}{.005} \\
\hline Within Groups & 47101.12 & 194 & 242.789 & & \\
\hline \multicolumn{6}{|c|}{ Different qualification } \\
\hline Between Groups & 5070.128 & 5 & 1014.02 & \multirow[t]{2}{*}{4.258} & \multirow[t]{2}{*}{.001} \\
\hline Within Groups & 46203.792 & 194 & 238.164 & & \\
\hline \multicolumn{6}{|c|}{ Marital status } \\
\hline Between Groups & 1316.607 & 4 & 329.152 & \multirow[t]{2}{*}{1.635} & \multirow[t]{2}{*}{.167} \\
\hline Within Groups & 39268.188 & 195 & 201.375 & & \\
\hline
\end{tabular}


The above table shows age, qualification, and marital status as independent variables and social mobility as a dependent variable. These results indicates that $(\mathrm{df}=3, \mathrm{MS}=834.558) \mathrm{f}=3.437, \mathrm{p}=(0.005<\alpha$ $=0.05)$. There was significant difference in mean scores of women's social mobility regarding their different age groups $(\mathrm{df}=5$, MS= 1014.02), $\mathrm{f}=4.258, \mathrm{p}=(0.001<\alpha=0.05)$. This shows that there is a significant difference in mean scores of women's social mobility regarding their qualification $(\mathrm{df}=4, \mathrm{MS} 329.152) \mathrm{f}=1.635, \mathrm{p}=(0.167<\alpha$ $=0.05$ ) shows that there is not significant difference in mean scores of women's participation in higher education with respect to their marital status.LSD post hoc test results of these comparisons are given below:

Table 4

LSD post hoc comparisons on age, qualification and marital status basis, where social mobility is dependent variable

\begin{tabular}{|c|c|c|c|c|c|}
\hline $\begin{array}{l}\text { Dependent } \\
\text { Variable }\end{array}$ & $\begin{array}{l}\text { (I) } \\
\text { Age }\end{array}$ & $\begin{array}{l}(\mathrm{J}) \\
\text { Age }\end{array}$ & $\begin{array}{l}\text { Mean Diff } \\
(\mathrm{I}-\mathrm{J})\end{array}$ & Std. Error & Sig. \\
\hline \multirow{7}{*}{$\begin{array}{l}\text { Social } \\
\text { Mobility }\end{array}$} & Below 25 & $26-30$ & $-8.38917^{*}$ & 2.64660 & .002 \\
\hline & & $\begin{array}{l}31-35 \\
\text { Above } 50\end{array}$ & $\begin{array}{r}-8.41644^{*} \\
-12.99739^{*}\end{array}$ & $\begin{array}{l}3.93260 \\
3.85840\end{array}$ & $\begin{array}{l}.034 \\
.001\end{array}$ \\
\hline & $\begin{array}{l}\text { (I) } \\
\text { Qualifications }\end{array}$ & & & & \\
\hline & Under-Graduate & Master & $-8.47146^{*}$ & 2.73851 & .002 \\
\hline & Others & $\begin{array}{l}\text { Mphil } \\
\text { Others } \\
\text { Graduate }\end{array}$ & $\begin{array}{r}-8.47431^{*} \\
-28.79839^{*} \\
23.77381^{*} \\
\end{array}$ & $\begin{array}{l}3.55699 \\
7.95814 \\
8.07216\end{array}$ & $\begin{array}{l}.018 \\
.000 \\
.004 \\
\end{array}$ \\
\hline & $\begin{array}{l}\text { (I) } \\
\text { Marital Status }\end{array}$ & $\begin{array}{l}\text { (J) } \\
\text { Age }\end{array}$ & $\begin{array}{l}\text { Mean Diff } \\
(\mathrm{I}-\mathrm{J})\end{array}$ & Std. Error & Sig. \\
\hline & $\begin{array}{l}\text { married } \\
\text { unmarried }\end{array}$ & $\begin{array}{l}\text { unmarried } \\
\text { divorced }\end{array}$ & $\begin{array}{r}5.99799^{*} \\
-16.38034^{*}\end{array}$ & $\begin{array}{l}2.40081 \\
6.59028\end{array}$ & $\begin{array}{l}.013 \\
.014\end{array}$ \\
\hline
\end{tabular}

LSD post hoc comparisons in table above indicated that women with age below 25 years had significantly different level of social mobility than women with age between26-35 but significantly greater social mobility than women of age 50 years or above.

Similarly, LSD post hoc comparisons indicated that women who were undergraduate had significantly greater social mobility than women with Master, MPhil or other qualification. Moreover, women with Master and MPhil qualifications had greater social mobility than women with other qualification. 
In the same manner, LSD post hoc comparisons in table above indicated that married women had different social mobility significantly than unmarried. Women who were divorced had significant difference in social mobility with respect to unmarried women.

Table 5

Correlation between cultural capital and women participation in higher education

Correlation between the cultural capital and participation of women in higher education

\begin{tabular}{llllll}
\hline Cultural capital & 61.4100 & 13.27944 & 200 & & \\
Participation & 66.8950 & 14.28089 & 200 & & 0.000 \\
\hline
\end{tabular}

Correlation between the cultural capital and social mobility of women

\begin{tabular}{llllll}
\hline Cultural capital & 61.410 & 13.27944 & 200 & & \\
& & & & $.429^{* *}$ & 0.000 \\
Social mobility & 84.980 & 16.05173 & 200 & &
\end{tabular}

\begin{tabular}{|c|c|c|c|c|c|}
\hline \multicolumn{6}{|c|}{$\begin{array}{l}\text { Correlation between the participation of women in higher education and } \\
\text { social mobility of women }\end{array}$} \\
\hline $\begin{array}{l}\text { Constraints in } \\
\text { Higher education }\end{array}$ & 84.980 & 16.05173 & 200 & \multirow{2}{*}{$.461^{* *}$} & \multirow{2}{*}{0.000} \\
\hline Social mobility & 66.895 & 14.28089 & 200 & & \\
\hline \multicolumn{6}{|c|}{ Parents' aspirations and life style/daily activities } \\
\hline Parents aspiration & 18.940 & 4.8241 & 200 & \multirow{2}{*}{.032} & \multirow{2}{*}{.653} \\
\hline $\begin{array}{l}\text { Life-style/daily } \\
\text { activity }\end{array}$ & 14.440 & 4.0519 & 200 & & \\
\hline \multicolumn{6}{|c|}{ Parents/husband qualification and women participation in higher education } \\
\hline $\begin{array}{l}\text { Parents/husband } \\
\text { profession } \\
\text { Participation in } \\
\text { higher education }\end{array}$ & 66.895 & 1.47716 & 200 & -.037 & .598 \\
\hline
\end{tabular}


The above table shows that the value of Pearson ' $r$ ' $(0.328)$ is significant at $\mathrm{p}=0.000(<\alpha=.01)$ for cultural capital and women participation in higher education. Similarly, ' $r$ ' $(0.429)$ is significant at $\mathrm{p}=0.000(<\alpha=.01)$ for cultural capital and social mobility of women. There is positive relationship for social mobility and constraints for women's participation, wherer' $(0.461)$ is significant at $\mathrm{p}=0.000(<\alpha=$ $.01)$. The value of Pearson ' $\mathrm{r}$ ' $(0.261)$ is significant at $\mathrm{p}=0.000(<\alpha=$ $.01)$ for learner's interest and family support. Similarly, ' $r$ ' (.269) is significant at $\mathrm{p}=0.000(<\alpha=0.01)$ for literacy and family support. The value of Pearson ' $r$ ' (.206) is significant at $p=0.003(<\alpha=.01)$ for social solidarity and family consciousness. For parents aspiration and life-style, the value of Pearson ' $r$ ' (.032) is not significant at $p=.653(>\alpha=.01)$. Similarly ' $r$ ' $(-.037)$ is not significant at $\mathrm{p}=.598(>\alpha=.01)$ for parents profession and women's participation for higher education.

The values shown above indicate positive relationship between cultural capital and participation of women in higher education, cultural capital and social mobility, the constraints for women in higher education participation and their social mobility, learner interest and family support, literacy and family cooperation in higher education, social solidarity and parent's consciousness, parents' aspirations and life style/daily activities, and between parents/husband qualification and women participation in higher education. Similarly, significant differences were also found between cultural capital of working and nonworking women, where cultural capital of working women was high as compared to non-working women.

\section{Discussion and Conclusion}

Xiulan and Yan (2019) explained that variations in cultural capital of different families influence educational attainment. Cultural capital is linked to participation of women in higher education. It means stronger the cultural capital of women, greater is their participation in higher education. It is evident that the cultural capital is an essential element for social mobility. If women's culture capital is stronger, their social mobility gets better. Also, women's participation in higher education is connected with the social mobility. The cultural capital of working women was found to be higher than cultural capital of nonworking women. Also, urban women had a higher cultural capital, as compared to rural women. Culture capital of women also differed according to their areas. 
The variations in social mobility were also found with respect to women's age and qualification. Also, greater participation of unmarried women was observed as compared to other groups. The differences direct to the fact that it is extremely crucial to educate the women of our society and efforts should be made to raise the cultural capital of the women of our society. According to Malika and Courtney (2011), when women are educated, they are given voice,they become economically independent, which enhances their personal confidence to obtain status in the community. This has underpinnings in parental cultural capital also, as parental cultural capital influence children's early and later educational achievement. According to Tzanakis (2011), children from higher financial status and backgrounds perform superior to those who having lower financial status and background. Cultural capital has also impact through parents' economic condition and education. Greater the qualification of parents/husband, greater is the women participation in higher education. According to Younas et al. (2015), the most significant determinants of social mobility are occupation and wealth. If women's cultural capital is week, then education can proved to be the only source to compensate it. This is what Yosso (2005) has concluded as, if someone is not born in literate families, one could get to the proficiencies of the upper class society and would ultimately socially mobilized through formal education and schooling.

We, therefore conclude that education for women must be the core value of our society to enhance their cultural capital as well as social mobility because greater is the cultural capital of women; better would be their participation rate in higher education and social mobility for them. Government and society must empower the woman by granting equal access to education, professions, and opportunities for their healthy social, emotional and economic development. Provision of legislative support is essential to working and non-working women that will also ultimately do some additions in their cultural capital, hence to enhance participation in higher education and onwards social mobility. 


\section{References}

Aldridge, S. (2001). Social Mobility. London: The Mall London, SW1A 2WH.

Benadusi, L. (2002). Equity and education. In In pursuit of equity in education (pp. 25-64). Springer, Dordrecht.

Blanden, J., \& Machin, S. (2004). Educational inequality and the expension of UK higher education. Scottich journal of Political Economy, 230-250.

Bourdieu, P., \& Richardson, j. (1986). Handbook of Theory and Research for the sociology of Education. Greenwood: Westpart Greenwood.

Bourdieu, P. (1977). Outline of a Theory of Practice. Volume 16. Cambridge University Press.

Brooks, A. C. (2008). Gross national happiness: why happiness matters for America--and how we can get more of it. New York: Basic Books.

Dimaggio, P. (1982). Cultural Capital and School Success: The Impact of Status CultureParticipation on the Grades of U.S. High School Students. American Sociological Review, 189-201.

Dumais, S. A. (2002). Cultural Capital, Gender, And School Success:

The Role of Habitus. Sociology Of Education, 75(1), 44-68.

Galiani, S. (2007). Social Mobility: What is it and why does it matter? Washington:Washington University in St. Louis.

Goodwin, R. N. (2003). Five Kinds of Capital: Useful Concepts for Sustainable Development. Global development and environment institute. Retrieved from

https://ageconsearch.umn.edu/record/15595/ 
Gorbunova, S.V. (2009) Accumulation of the human capital in real economy workers, Cand. Sci.(Econ.)Dissertation, Yekaterinburg: Int Ekon. UrO RAN.

Jæger, M. M. (2010). Does Cultural Capital Really Affect Academic Achievement?Danish Social Science Research Council. Retrieved from https://journals.sagepub.com/doi/10.1177/0038040711417010

Košutić, I. (2017). The Role of Cultural Capital in Higher Education Access and

Institutional Choice. c e p s Journal, 7(1),149-169. Retrieved from: $\quad$ https://files.eric.ed.gov/fulltext/EJ1137837.pdf

Lareau, A. (2000). Home advantage: Social class and parental intervention in elementary education. Lanham, MD: Rowman \& Littlefield Publishers, Inc.

Malik, S. \&Courtney, K. (2011). Higher education and women's empowerment in Pakistan. Gender and Education, 23 (1), 29-45.

Nath, D. S. (2014). Higher Education and Women Participation in India. Journal of Business Management \& Social Sciences Research (JBM\&SSR), 3(2), 43-47.

Nazimuddin, S. (2014). Social Mobility and Role of Education in Promoting SocialMobility. International Journal of Scientific Engineering and Research (IJSER) , 3(7), 176-179.

Qureshi, R., Pirzado, P. \& Nasim, S. (2007) Schooling in Rural Sindh, Pakistan, in: R.Qureshi \& J.F.A. Rarieya (Eds.) Gender and Education in Pakistan Karachi: Oxford University Press.

Rabbani, S., Zeeshan, M., \& Saleem, H. (2015). Cultural perception of womenempowerment in chakwal city. Department of Anthropology, PMAS-Arid Agricultural University, Rawalpindi. 
Shah, M., Khan, R., Naushad, K., Jadoon, M., \& Alam, I. (2006). Women Being the MostNeglected Agent in the South Asian Societies. Pakistan Journal of Life and Social Sciences, 4(1-2), 81-85.

Sullivan, A. (2002). Bourdieu and education:how useful is bourdieu's theory for researchers? The netherlands' jounal of social sciences, $38(2), 144-166$.

Throsby, D. (1999). Cultural Capital. Journal of Cultural Economics, 23(1-2), 3-12.

Tzanakis, M. (2011). Bourdieu's Social Reproduction Thesis and The Role of CulturalCapital in Educational Attainment: A Critical Review of Key Empirical Studies. Critical Review, 11(1), 76-90.

Valdez, C. R., Mills, M. T., Bohlig, A. J., \& Kaplan, D. (2012). The Role of ParentalLanguageAcculturation in the Formation of Social Capital: Differential Effects on High-risk Children. ChildPsychiatry, 44(2), 334-350.

Wood, H. M. (2008). Beyond Access: Cultural Capital's Increasing Significance in Selective College Admissions. Unpublished B.A Thesis, Faculty of Wesleyan University.

Xiulan, Y. \& Yan, H. (2019). How humble families produce "successful descendants" - class advancement from the perspective of cultural capital, Chinese Education \& Society, 52(5-6), 301320. DOI: $10.1080 / 10611932.2019 .1693802$

Yamamoto, Y., \& Brinton, M. C. (2015). Cultural Capital in East Asian EducationalSystems: The Case of Japan. Sociology of Education,83(1), 67-83.

Younas, M. R., Sakhawat, T., Chaudhry, A., \& Nasir, A. (2015). Social mobility and cultural resource management: Discourse analysis. Science International, Lahore. 27(1), 687-689. 
Yosso, T. J. (2005). Whose culture has capital? A critical race theory discussion ofcommunity cultural wealth. Race Ethnicity and Education, 8(1), 69-91.

\section{Citation of this Article:}

Uzair ul Hassan, M., Parveen, I., \& Saleem, S. (2019). Implication of cultural capital in women's higher education participation and social mobility. Pakistan Journal of Education, 36(3), 145-162.

DOI: $10.30971 /$ pje.v36i3.1184.g204

To link this article: http://dx.doi.org/10.30971/pje.v36i3.1184 